\title{
Política habitacional de baixa renda e a atuação do capital privado: o Programa de Arrendamento Residencial em Presidente Prudente (SP)
}

\author{
Low-Income housing policy and the role of private capital: the Residential \\ Leasing Program in Presidente Prudente, São Paulo, Brazil
}

Sibila Corral de Arêa Leão Honda

Arquiteta e Urbanista, doutora em Arquitetura e Urbanismo pela Universidade Presbiteriana Mackenzie, docente e coordenadora do curso de Arquitetura e Urbanismo da Universidade do Oeste Paulista (Unoeste), Presidente Prudente, SP Brasil, e-mail: sibila@unoeste.br

\section{Resumo}

Este artigo visa a contribuir para uma análise crítica sobre a produção da habitação de baixa renda pela iniciativa privada em cidades médias no Brasil, entre os anos 1999 e 2008, verificando seus efeitos no espaço urbano. Aborda o papel dos municípios, pós-Constituição Federal de 1988, com ênfase no Programa de Arrendamento Residencial (PAR), instituído em 1999 pelo Governo Federal; e tem como estudo de caso Presidente Prudente, município localizado no oeste do estado de São Paulo. Foca a discussão na relação entre as políticas urbanas e habitacionais, assim como na implantação de empreendimentos executados pela iniciativa privada e financiados pela Caixa Econômica Federal, por meio do PAR, e seus mecanismos e efeitos na produção do espaço urbano. Evidencia-se a ausência de diretrizes específicas voltadas para a política habitacional no âmbito da política urbana deste município, induzindo a uma atuação direta do capital privado, que contribui para a produção de espaços urbanos segregados e excludentes.

Palabras-clave: Política urbana. Habitação de interesse social. Expansão urbana. Segregação socioespacial. Programa de arrendamento residencial.

\section{Abstract}

This paper intents to contribute to a critical analysis on the production of low-income housing by the private sector in medium-sized cities in Brazil, between 1999 and 2008, examining their effects on urban space. Discusses the role of municipalities, post-1988 Brazilian Federal Constitution, with emphasis on the Programa de Arrendamento Residencial (PAR), established in 1999 by the Brazilian Federal Government, and taking as a case study Presidente Prudente, a city located west of Sao Paulo State. Its focus is to discuss the relationship between the urban and housing policies and enterprises implementation by the private initiative and funded 
by the Caixa Economica Federal, through the PAR, its mechanisms and effects on the production of urban space. It is evident in the urban policy of this city that the absence of specific guidelines towards housing policy leads to a direct action of private capital, which contributes to the production of urban segregation and exclusion.

Keywords: Urban policy. Social interest housing. Urban expansion. Socio-spatial segregation. Residential leasing program.

\section{Introdução}

Este artigo tem como foco a compreensão sobre a recente produção da habitação de baixa renda no espaço urbano de cidades de porte médio. Com análise de Presidente Prudente, cidade média do interior do estado de São Paulo, discute-se a produção da habitação social por agentes privados, por meio de estudo de caso do Programa de Arrendamento Residencial (PAR) da Caixa Econômica Federal.

Em um contexto de intenso processo de urbanização, ocorrido principalmente a partir da década de 1960 no Brasil, inúmeros são os desafios relativos às políticas públicas e à gestão e organização do território municipal. Essa urbanização elevou seriamente a demanda por moradia, num quadro de precariedade, que inicialmente foi visível nos grandes centros urbanos, mas que tem se propagado rapidamente para as cidades médias; estas compreendidas como cidades não metropolitanas, com população entre 100 e 500 mil habitantes, que apresentam crescimento populacional sistemático, com nível de serviços públicos satisfatórios (FELDMAN, 2003).

Parte-se do pressuposto de que o enfrentamento dos graves problemas que atingem as cidades brasileiras requer soluções articuladas de planejamento e gestão urbanos. Nesse contexto, a formulação de políticas públicas adequadas, particularmente aquelas relativas ao uso do solo urbano, à habitação, à infraestrutura de saneamento básico e de transportes, ao meio ambiente etc. deve contribuir para a construção de ambientes urbanos equilibrados e justos.

Principalmente a partir da Constituição Federal de 1988, as temáticas da política urbana e da gestão das cidades, no Brasil, passaram a ocupar um lugar de destaque em diversas esferas institucionais, políticas e sociais. Com a promulgação dessa Constituição ocorreu o fortalecimento do Município, por meio da ampliação da autonomia política, administrativa e financeira.
Na esfera das políticas públicas, a questão da política habitacional passou a ser central e estratégica para os Municípios, uma vez que um dos principais problemas é a provisão de moradias adequadas à grande parcela da população, apesar da competência nessa área ser das três esferas de governo: federal, estadual e municipal. Dessa forma, apesar de o Município não ter competência isolada sobre a política habitacional, a responsabilidade de implementação de uma política urbana justa e equitativa, com objetivos de justiça social e de qualidade de vida, prevista no Estatuto da Cidade (Lei Federal n. 10.257/2001) inclui estratégias na escala local para a elaboração de políticas públicas setoriais, principalmente a da habitação.

A partir do final da década de 1980, um conjunto de crises políticas e institucionais no âmbito da política federal fez com que as áreas da habitação e do desenvolvimento urbano permanecessem sem contar com recursos financeiros expressivos e sem capacidade institucional de gestão (MINISTÉRIO DAS CIDADES, 2004). Com isso, as iniciativas em programas habitacionais por parte de administrações municipais disseminaram-se e ganharam maior legitimidade durante os anos de 1990 e inicio dos anos 2000, na medida em que foram também apoiadas pelas novas políticas habitacionais federais brasileiras. Nesse contexto, surgiram novas linhas de financiamento de moradia promovidas pelo Governo Federal por meio da Caixa Econômica Federal que visavam a beneficiar os governos estaduais e municipais, apoiadas na iniciativa privada.

Assim, ocorreu a entrada de uma fatia da iniciativa privada na produção de unidades habitacionais, para o mercado de interesse social, por meio de vários programas governamentais, entre eles o Programa de Arrendamento Residencial (PAR), que passou a constituir uma oportunidade para o Governo Municipal resolver parcelas significativas de seus problemas relacionados à demanda crescente por habitação. 
No entanto, apesar da possibilidade de contribuição com a construção de novas moradias para a baixa renda pelo setor privado, o Município destaca-se como gestor. É, portanto, fundamental que atue de forma constante na regulação da atuação do mercado imobiliário em consonância com a política de desenvolvimento urbano e com as diretrizes que vão ao encontro dos propósitos da função social da cidade.

Paralelamente, como parte do processo de planejamento urbano, atualmente os Municípios brasileiros vêm incorporando os instrumentos urbanísticos fundamentais à questão, e, entre eles a Zona Especial de Interesse Social - ZEIS (artigo 4º da Lei n. 10.257/2001), área a ser delimitada pelo Poder Público municipal, no Plano Diretor, destinada à implantação de habitação de interesse social. Entretanto, tal possibilidade não necessariamente vem sendo traduzida da mesma maneira por todos os Municípios brasileiros, por motivos diversos, seja pela sua condição financeira, pela incapacidade político institucional, ou mesmo, pelo contínuo descaso em relação às questões urbana e habitacional.

No caso do município de Presidente Prudente, a ausência histórica de políticas públicas inclusivas contribuiu para que a produção do espaço urbano ocorresse segundo os interesses do capital, resultando em uma mancha urbana dispersa e fragmentada composta de espaços altamente segregados e excludentes.

Esse município atende à orientação legal da política urbana federal em relação à instituição de um Plano Diretor voltado a direcionar o seu desenvolvimento urbano a partir da Constituição Federal de 1988. Apesar disso, evidencia-se um desinteresse de ação, de regulação legal e de estímulo à redução da segregação no espaço urbano pelo poder público municipal, particularmente na definição de áreas voltadas para a implementação de moradias para população de baixa renda.

A lacuna em relação à habitação social em Presidente Prudente, representada pela carência de incentivos e pela alta taxa de população com alta vulnerabilidade social ${ }^{1}$, gera grande necessidade de investimentos na construção e financiamento de moradias para população mais carente.
Para atender parcialmente à crescente demanda por habitação de interesse social, em 2001, Presidente Prudente foi um dos municípios beneficiados no estado de São Paulo pelo Programa de Arrendamento Residencial (PAR), criado em 1999 pelo Governo Federal. Entre 2003 e 2006 foram executados cinco empreendimentos com características distintas e com os dois patamares de renda estipulados pelo programa: PAR 1 (para renda de até seis salários mínimos) e PAR 2 (para renda de até três salários mínimos).

No âmbito desse contexto, o artigo procura discutir a produção da habitação de baixa renda na cidade de Presidente Prudente, promovida por agentes privados no âmbito do Programa de Arrendamento Residencial (PAR) da Caixa Econômica Federal e os seus efeitos na produção social do espaço urbano.

Busca-se verificar se a recente produção de habitação tem considerado os novos aspectos políticos e legais a partir da Constituição Federal de 1988, assim como a incorporação dos instrumentos urbanísticos no âmbito municipal, ou se continua reproduzindo a localização e as estratégias de implantação de habitação social historicamente identificadas no país.

\section{Produção do espaço urbano e políticas públicas: efeitos e agentes}

Monteiro (1982, p. 12) conceitua política pública como sendo a "ação (ou inação) conscientemente escolhida e orientada para um determinado fim". Cunha e Cunha (2002) focam na coletividade e nas demandas da sociedade, concretizando os direitos sociais (Direito Coletivo) e sua legitimidade; embora esclareçam que, apesar dessa legitimidade na criação das políticas públicas pelo Estado, "elas englobam preferências, escolhas e decisões privadas, podendo (e devendo) ser controladas pelos cidadãos" (CUNHA; CUNHA, 2002, p. 12).

A atenção a diferenças no contexto das políticas públicas é fundamental na análise do objeto políticas urbanas, tanto conceitualmente quanto

\footnotetext{
1 Segundo a Fundação Sistema Estadual de Análise de Dados (Seade), em 2000, 24,6\% do total da população do município de Presidente Prudente apresentava alta vulnerabilidade social, acima da média do estado de São Paulo, que era de 17,6\% (SEADE, 2000).
} 
no estudo das ações e seus resultados. Em relação a estes, é crucial a constante adequação da gestão das políticas, pois podem ser observados direcionamentos imprevisíveis, cujos rumos impõem reformulações. Mas, atentando para Villaça (1999, p. 180), as políticas urbanas "devem referir-se às reais ações e às propostas consequentes de ação do Estado sobre o urbano".

As políticas urbanas implicam uma dimensão de natureza real, da ação. No exercício da sua vontade é necessária a análise dos atores e das regras da ação política. Entretanto, as decisões não são justas a todos, havendo grande diversidade de interesses, e o discurso não reflete necessariamente a realidade da ação, e muitas vezes, há uma imposição legal no espaço urbano, criando, reproduzindo ou reforçando características de expansão e/ou segregação urbanas (LACAZE, 1999).

Segundo Alvim, Castro e Zioni (2010), as políticas urbanas podem ser identificadas como políticas públicas voltadas às demandas e práticas sociais locais; e afirmam que são várias as áreas passíveis de atuação do poder público no âmbito local, sendo a política habitacional considerada uma política urbana especifica, setorial. No entanto, mesmo sendo parte da política urbana, a política habitacional pode envolver programas de responsabilidade de qualquer um dos três níveis de governo: federal, estadual e municipal.

Rolnik e Pinheiro (2004, p. 73) afirmam que a "política habitacional é instrumento para alcançar o direito à moradia e passa, necessariamente, pela esfera municipal". Esses autores informam que essa política apresenta importância significativa na gestão e no desenvolvimento urbanos, refletindo nos aspectos de produção social do espaço urbano: territorial (pela expansão, reprodução e adensamento), social (com segregação) e econômico. Assim sendo, seu direcionamento deve ser dado com foco na sociedade à que se aplica, na satisfação de suas necessidades e na sua capacidade (econômica e de reprodução).

Para alcançar o propósito de cada política urbana, faz-se necessário que as dimensões política e técnico-científica estejam alinhadas, revendo e reordenando os instrumentos de planejamento e gestão, com atenção a questões de valor e objetivos. Como também é fundamental a participação popular, inclusive quando em disputas de grupos de interesses; sendo importante verificar quais os agentes e suas reais forças na construção da realidade.

Conforme Valladares (1983), a produção do espaço urbano pode ser vista por meio da ação de um conjunto de agentes: o proprietário fundiário, o loteador, o corretor imobiliário, o Estado e o morador. Marques (2005) informa que em um limite do processo constam os agentes envolvidos com a comercialização no mercado imobiliário urbano; no outro extremo, encontram-se os proprietários fundiários; e, em posições intermediárias, encontram-se os construtores e os incorporadores, sendo que estes articulam os demais, uma vez que definem o produto imobiliário a ser lançado e sua localização.

A produção do espaço urbano capitalista conforme afirma Corrêa (1999) é fragmentado, reflexo e condicionante social, com jogos de interesse, articulados por agentes que produzem e consomem espaço, sendo que a atuação do Estado visa a criar condições para os processos de acumulação e de reprodução das classes sociais, por meio de mecanismos que levam à segregação socioespacial.

Nas análises e discussões sobre segregação espacial elaboradas por Villaça (1998), o autor deixa bastante explícito que esse processo é dialético, ou seja, a segregação de uns provoca a segregação de outros, imediatamente, e que o processo de dominação - econômica, política e social - necessita da segregação como forma de controle.

A segregação socioespacial é uma característica bastante relevante nas cidades, segundo Caldeira (2003), pois as normas e legislações que organizam o espaço urbano estão baseadas em padrões de diferenciação e de separação.

Para Santos (2005), o poder público também estimula a especulação e a existência de vazios urbanos, pois, incapaz de resolver o problema da habitação, ele empurra a população com menos recursos para as periferias; e, dessa forma, age direta e indiretamente na geração de problemas urbanos, mas com discurso ideológico diferente.

0 processo de produção do espaço urbano no município de Presidente Prudente revela a existência de grande segregação socioespacial principalmente quando se analisa a sua estrutura urbana e a distribuição dos conjuntos habitacionais de baixa renda produzidos, desde a década de 1960, por agentes públicos e privados, como se pode ver a seguir. 


\section{O processo de produção do espaço urbano em Presidente Prudente e a habitação de baixa renda}

Presidente Prudente, cidade localizada no oeste paulista, na região conhecida como Alta Sorocabana, teve sua base de colonização apoiada na produção agropecuária e na implantação da estação ferroviária no início do século XX (inaugurada em janeiro de 1919).

A definição de sua estrutura urbana relacionou-se diretamente com a abertura de dois loteamentos - Vila Goulart e Vila Marcondes; o primeiro foi aberto junto à estação ferroviária que estava em construção em 1917, e o segundo, em 1919, como suporte ao comércio de terras rurais, situando-se do lado oposto da linha férrea.

Ainda nos primeiros anos, a Vila Goulart assumiu o papel de centro comercial e área residencial das famílias mais abastadas, enquanto a Vila Marcondes passou a atrair as empresas de beneficiamento agrícola ao longo da linha ferroviária e bairro residencial das classes mais baixas. A cidade, assim como sua região, dependia diretamente da produção agrícola (HONDA, 2000).

Em 1921, o município de Presidente Prudente foi criado legalmente como centro político e administrativo regional. A produção cafeeira foi a base econômica da região até início da década de 1930, quando se observa a entrada do algodão na produção agrícola e se intensifica a pecuária de corte. A cidade assumiu papel de base comercial, de prestação de serviços e de beneficiamento da produção agrícola para a Alta Sorocabana.

A expansão urbana em Presidente Prudente sempre ocorreu de forma mais dinâmica na direção sudoeste, como prolongamento da Vila Goulart. Entre 1920 e a primeira metade da década de 1950, a cidade apresentou significativa expansão territorial, sem planejamento e sem regularização legal. A informalidade na organização fundiária do território prudentino foi a prática, atingindo diretamente a produção da cidade, com grande expansão da malha urbana (HONDA, 2000).

A estrutura política da cidade se formou baseada no coronelismo, apoiada inicialmente nas figuras dos 'Coronéis' Goulart e Marcondes, reproduzida ao longo dos anos. Abreu (1996) afirma que a 'Revolução de 1930' não alterou as práticas políticas prudentinas; do coronelismo passou-se para o populismo.

Spósito (1990) afirma que a partir da mudança do sistema de governo em 1964 ocorreu certa moralização, motivada pela possibilidade de ampliação da arrecadação municipal pelo poder público, tendo provocado regularização de loteamentos e lotes.

Em 1968, o Centro de Pesquisas e Estudos Urbanísticos (CPEU) da Faculdade de Arquitetura e Urbanismo da Universidade de São Paulo (FAUUSP), elaborou o primeiro plano diretor para a cidade. Também nesse ano, o município foi beneficiado com a construção do primeiro conjunto habitacional com financiamento do BNH, o Parque Continental, localizado na franja urbana da cidade, formado por 142 casas unifamiliares. Importante observar que o loteamento onde foi implantado esse empreendimento estava aberto desde 1962, em área bastante isolada na região sul da cidade.

Durante as décadas de 1970 e 1980, a cidade apresentou grande expansão territorial urbana; mas sem acompanhamento do crescimento demográfico urbano (SPÓSITO, 1983). A expansão urbana pode ser mais sentida na direção sudoeste, criando grandes vazios no traçado da cidade por longos períodos de tempo. A malha urbana praticamente dobrou nesse período.

A partir da década de 1970 começa a se configurar um espaço urbano altamente segregado na cidade, segundo Marisco (2003), com participação direta de vários agentes - poder público local, incorporadores imobiliários e proprietários fundiários - que agiram no direcionamento da expansão urbana, assim como na destinação das áreas e regiões voltadas às populações de alta e baixa renda. Entre os anos de 1975 e 1977, ocorreu grande elevação dos preços dos terrenos, com ampliação do processo de implantação de loteamentos na cidade.

Entre 1973 e 1981, a cidade apresentou uma realidade extremamente favorável à reprodução do capital. No entanto, muitos loteamentos abertos na cidade somente receberam moradores após serem utilizados para construção de conjuntos habitacionais. $\mathrm{O}$ aumento de impostos e o processo de implantação desses empreendimentos na franja urbana do município incentivaram o deslocamento da população de menor renda, com redução da ocupação urbana das áreas mais centrais da cidade, reforçando ainda mais a segregação socioespacial. 
A maior parte dos conjuntos de moradia de interesse social, entre os anos de 1976 e 1980, foi implantada na região oeste da cidade (HONDA, 2011).

Apesar dessas características, é importante ressaltar que esses empreendimentos serviram para estimular a incorporação privada em novas áreas da periferia urbana, principalmente a oeste e norte da cidade; reproduzindo o processo segregador.

A partir de 1983, com um novo Governo Municipal $^{2}$, e tendo cessado o fluxo de financiamento externo no Brasil, resultando em crise nacional, ocorreu uma mudança no percurso histórico de oferta de lotes e loteamentos no município, com poucos investimentos públicos em habitação social ou privados em terra (TORREZAN, 1992).

A nova Constituição Federal foi sancionada em 1988, com inclusão de capítulo específico sobre política urbana e exigência de Plano Diretor Municipal.

A Companhia de Desenvolvimento Habitacional e Urbano (CDHU), da Secretaria de Habitação do Estado de São Paulo, criada em 1989, aprovou e financiou, entre 1990 e 1993, um total de 1.552 unidades residenciais em Presidente Prudente (FERNANDES, 1998). E, durante os anos de 1990 e 1993, 2.757 unidades habitacionais foram construídas e entregues por meio de financiamento do Programa de Ação Imediata de Habitação (PAIH), do Governo Federal.

Na gestão municipal compreendida entre 1993 e 1996, houve concessão de Direito Real de Uso de 4.013 lotes urbanizados no município, sem participação de Governo Federal ou Estadual, mas todos em glebas localizadas além da malha urbana, nas regiões norte e noroeste. No último ano desse Governo Municipal, foi aprovado o novo plano diretor para a cidade por meio da Lei Municipal n. 29/1996.

Durante a presidência de Fernando Henrique Cardoso (1995-2002), a Política Nacional de Habitação (PNH) visava à descentralização da execução dos programas habitacionais, com incentivo a ações dos Governos Municipais como agentes promotores de habitação social. Paralelamente, durante a gestão municipal compreendida no período de 1997 a 2000, cinco empreendimentos de habitação social foram executados na cidade, sendo quatro financiados pela CDHU e um particular com verba da Caixa Econômica Federal.

Em 1999, foi editada a Medida Provisória n. 1.823/99, que criou o Programa de Arrendamento Residencial (PAR), pelo Governo Federal, como nova forma de agenciamento da habitação. Esse programa veio a beneficiar Presidente Prudente com a construção de habitações para a população de baixa renda entre os anos de 2003 e 2006. Concomitantemente, em janeiro de 2008, foi aprovada a revisão do Plano Diretor (Lei Municipal n. 151/2008).

Ao longo do processo de produção do espaço urbano de Presidente Prudente evidencia-se que a estruturação da cidade permanece com áreas segregadas; o setor sudoeste atrai os loteamentos e os condomínios de alta renda; a oeste e a norte localizam-se as camadas de menor poder aquisitivo.

O processo de expansão da malha urbana ocorre com manutenção de grandes vazios urbanos, muito embora o município, entre 1996 e 2008, tenha instituído dois planos diretores que incorporaram parte dos princípios constantes na Constituição Federal e no Estatuto da Cidade.

\section{Política urbana em Presidente Prudente: planos diretores posteriores a 1988 e a questão da habitação}

0 processo de expansão urbana ocorrido em Presidente Prudente até o final da década de 1960 não teve regulação urbanística ou normatização legal, podendo ser verificados vários períodos de ampliação da malha e do perímetro urbano.

Em 1968, o município foi objeto do primeiro plano diretor - denominado Plano Diretor de Desenvolvimento Integrado (PDDI) - com metodologia especificada pelo Serviço Federal de Habitação e Urbanismo (SERFHAU), desenvolvido pelo CPEU da FAUUSP. Marisco (1997) ressalta que o PDDI visava a políticas e diretrizes para todo o município de Presidente Prudente; mas estas não foram implantadas. Como decorrência do PDDI, foi instituído o primeiro zoneamento urbano (Lei n. 1.583/1973). Ambos ficaram em vigor até o ano de 1996.

\footnotetext{
${ }^{2}$ Foi eleito para prefeito o Sr. Virgílio Tiezzi Júnior na primeira eleição municipal ocorrida a partir do processo de redemocratização no país.
} 
Durante os primeiros setenta anos de formação dessa cidade, não houve uma política urbana local clara. Todas as ações do poder público municipal resultaram de decisões não planejadas oficialmente, mantendo o padrão de política populista.

Entretanto, o ano de 1988, segundo Spósito (1990), sinalizou uma transformação na política habitacional municipal, apresentando um discurso pela busca da resolução do problema habitacional, inclusive com utilização da desapropriação ou por meio de parcerias com empresas privadas para construção de moradias. Nesse ano, foi sancionada a Constituição Federal.

No ano de 1990, foi aprovada a lei orgânica do município de Presidente Prudente. Com base nessa lei e decorrente da obrigatoriedade definida pelas Constituições Federal (1988) e Estadual Paulista (1989), em 1996, foi elaborado e aprovado o novo plano diretor municipal (PD), como Lei Municipal n. 29/1996.

Entre as políticas setoriais definidas nesse plano, na seção sobre a política habitacional, constam diretrizes gerais de ação pública, que, no entanto, não foi objeto de detalhamento e nem posteriormente de legislação especifica.

Do conjunto dos instrumentos previstos no PD, foram aprovados o zoneamento, o parcelamento ou edificação compulsórios, o IPTU progressivo no tempo, e as ZEIS. No entanto, somente o zoneamento foi alvo de legislação específica, com a Lei Complementar Municipal n. 31/1996, que instituiu o Zoneamento de Uso e Ocupação do Solo Urbano. Os demais não foram objetos de detalhamento e nem sequer as áreas ou regiões prioritárias passíveis de aplicação desses instrumentos foram definidas.

Em 1998, foi aprovada a primeira lei municipal que trata de ZEIS, a Lei Complementar Municipal n. 53/1998, que não chegou a definir as áreas passíveis de aplicação do instrumento. Esta lei possibilitou ao proprietário imobiliário interessado o poder de requerer junto à Prefeitura a alteração do zoneamento de sua área para ZEIS.

Nesse período, as políticas habitacionais de âmbito municipal não buscaram o controle do espaço urbano, assim como não visaram a incentivar novos projetos e programas habitacionais. A ação pública se mostrou apenas receptiva a novos empreendimentos.

No ano de 2001, foi sancionada a Lei Federal n. 10.257/2001 (Estatuto da Cidade), que regulamenta os artigos 182 e 183 ("Da Política Urbana") da Constituição Federal. Apesar das maiores possibilidades de aplicação de instrumentos urbanísticos para controle, planejamento e gestão das cidades, a cidade de Presidente Prudente não assumiu imediatamente a posição de revisão do Plano Diretor. Porém, em 2003, o poder público municipal aprovou uma nova Lei de Zoneamento de Uso e Ocupação do Solo Urbano (Lei Complementar n. 128/2003), com inclusão de dois outros instrumentos urbanísticos, embora não definidos no Plano Diretor, que deveria ter sido revisado: o Estudo de Impacto de Vizinhança (EIV) e a Outorga Onerosa do Direito de Construir.

Em 2005 foi divulgada a Resolução n. 34 do Conselho Nacional das Cidades, que estabeleceu que os planos diretores municipais deveriam incluir os objetivos, temas prioritários e estratégias de desenvolvimento e reorganização territorial municipais, entre outros aspectos.

Somente em 2007 é que ocorreu o processo de discussão e revisão do Plano Diretor, tendo sido aprovado no início de 2008 por meio da Lei Municipal n. 151/2008. No entanto, esse novo plano não considera a resolução acima citada, e mais uma vez não identifica áreas passíveis de aplicação dos instrumentos urbanísticos aprovados.

No novo Plano Diretor, a política habitacional basicamente repetiu os artigos do PD anterior, e, da mesma maneira, não fez menção a ZEIS, deixando que esse assunto fosse tratado apenas na Lei Complementar Municipal n. 153/2008, que dispõe sobre o novo Zoneamento de Uso e Ocupação do Solo Urbano. Essa lei, por sua vez, também não define as áreas que deveriam ser alvos de ZEIS, mantendo a decisão do proprietário imobiliário para solicitar a alteração do zoneamento de sua gleba para ZEIS, de acordo com seus interesses particulares. Ou seja, a função social da propriedade é claramente descartada.

Embora esse novo PD tenha incorporado alguns instrumentos urbanísticos, observa-se que a maioria deles sequer foi regulamentada, ficando a produção do espaço urbano à mercê do mercado privado de terras. Dessa forma, verifica-se que, de uma política municipal populista, o poder público local tem utilizado política de beneficiamento do mercado.

As políticas urbana e habitacional municipais em Presidente Prudente têm se mostrado bastante 
vagas e permissivas, possibilitando ações diretas especulativas e segregadoras no espaço intraurbano.

Ainda hoje, em relação à definição legal de áreas para habitação social, especificamente as ZEIS, a Prefeitura não tem intenção de proceder à sua delimitação, segundo entrevista realizada com os funcionários da Secretaria de Planejamento, Desenvolvimento Urbano e Habitação Municipal. Isso porque a prefeitura considera que haveria diminuição da oferta de moradia popular pela iniciativa privada e restrição da capacidade de ação do poder público municipal.

Dessa forma, a implantação de habitação social na cidade tem se mostrado dependente das ações públicas - federais e estaduais, e privadas. Conjuntos habitacionais têm sido construídos no município sem direcionamento do Governo local sobre áreas prioritárias e sem planejamento para diminuir vazios urbanos ou áreas subutilizadas, o que contribuiria para a redução da segregação socioespacial (HONDA, 2011).

No âmbito do Programa de Arrendamento Residencial (PAR), cujo convênio entre a Caixa Econômica Federal e a Prefeitura Municipal foi assinado em 2001, nos anos de 2003 a 2006 foram construídos cinco empreendimentos que serão analisados nas próximas seções. Buscou-se verificar a participação efetiva do poder público e os efeitos sobre a produção do espaço urbano prudentino.

\section{O Programa de Arrendamento Residencial (PAR) em Presidente Prudente}

Em 1998, ocorreu a reeleição do então Presidente da República, Fernando Henrique Cardoso, para o quadriênio 1999-2002. A Política Nacional de Habitação (PNH) em vigor à época apresentava, entre os aspectos básicos, a descentralização da execução de programas de habitação, saneamento e infraestrutura; atentando às diferenças regionais da sociedade e suas demandas. No âmbito dos programas de financiamento da política habitacional, destaca-se o Programa de Arrendamento Residencial (PAR), instituído pela Medida Provisória n. 1.823/1999, transformada na Lei n. 10.188/2001.

O PAR foi criado como resposta ao não atendimento à população de menor renda (até seis salários mínimos) no financiamento de habitação nos demais programas implementados até então. Além disso, havia a constatação de que $65 \%$ dos ocupantes dos imóveis financiados como moradia de interesse social pela Caixa Econômica Federal não estavam mais nas mãos dos adquirentes originais (CAIXA ECONÔMICA FEDERAL, 2008), fato que demandava repensar o modelo de aquisição com dinheiro público da habitação de baixa renda. A principal diferença do PAR consistia na não aquisição direta do imóvel, por meio da figura do arrendamento, em que o arrendatário teria a opção de compra depois de transcorrido tempo de residência no imóvel.

A definição de prioridades para implantação do programa deveria ser feita pelo poder público municipal, baseado no Plano Diretor aprovado, segundo as áreas caracterizadas como prioritárias ou ZEIS, por meio de estudos de expansão urbana e deficit habitacional; ou seja, a relação com a política urbana local seria essencial.

Bonates (2008) afirma que, a partir de 2003, com o Governo do Presidente Luis Inácio Lula da Silva, ocorreram alterações legais no programa, que modificaram o perfil de produção do PAR: de conjuntos residenciais localizados na malha urbana, para conjuntos localizados fora da malha, podendo ser verificado maior atendimento à população de renda mais baixa, em função da aquisição de terras mais baratas pela iniciativa privada.

Essa tendência possibilitou o retorno da implantação de empreendimentos de habitação social nas áreas periféricas, com menor inclusão da população beneficiada aos serviços e infraestruturas urbanas. Verifica-se, dessa maneira, o retorno das características tradicionais para financiamento de moradia de interesse social.

Em Presidente Prudente, os cinco empreendimentos executados com financiamento do PAR foram implantados em locais definidos pelo capital imobiliário, em geral nos limites da franja urbana, ou em bairros afastados do centro da cidade.

Como já destacado, nessa cidade, as zonas especiais para habitação de interesse social são definidas de acordo com o interesse do proprietário de terras urbanas que tem liberdade para solicitar a alteração do zoneamento para ZEIS. Dessa forma, proprietários visando a repassar suas áreas para construção de habitação social pelos Governos Federal ou Estadual têm liberdade de solicitar a alteração do zoneamento de suas glebas, como tem ocorrido com 
as áreas onde são implantados os conjuntos financiados pela CDHU no município.

Assim, a Prefeitura não se envolveu na definição de áreas ou regiões prioritárias, como também não indicou com informação atualizada o deficit habitacional urbano. A própria candidatura da cidade ao Programa foi iniciativa de agentes privados locais (imobiliárias e proprietários de terras), interessados em investir no mercado de habitação social.

A distribuição espacial dos empreendimentos na malha urbana foi baseada na oferta de áreas privadas, sem relação com deficit habitacional setorizado, disponibilidade de serviços e/ou equipamentos urbanos, ou outro levantamento elaborado. A definição do patamar de renda alcançada, definindo a categoria do PAR (se PAR 1, para renda de até seis salários, ou PAR 2, para renda de até três salários), apoiou-se exclusivamente na disponibilidade de verba do banco financiador (Caixa Econômica Federal); ou seja, no limite de verba liberada para a Gerência de Desenvolvimento Urbano da Caixa Econômica Federal (GIDUR) de Presidente Prudente para financiamento em cada patamar do programa.

A Prefeitura Municipal de Presidente Prudente, nos processos do PAR, participou apenas na aprovação dos projetos junto à Secretaria de Planejamento, e colaborou com parte dos cadastramentos de interessados.

Os conjuntos habitacionais executados diferem-se quanto à tipologia construtiva, área de implantação, quantidade de famílias beneficiadas, valores de financiamento, e relação com a estrutura urbana. Mas a reprodução das características de implantação da habitação social em áreas distantes na malha urbana foi mantida nos conjuntos.

Analisando os cinco empreendimentos do PAR, além da questão da implantação periférica, verifica-se que, apesar de as localizações diferirem entre si, eles se situam em áreas de concentração de população de menor poder aquisitivo, incluindo áreas na zona leste (Laura), zona norte (Atalaia), zona sul (Esmeralda e Monte Carlo) e região noroeste (Bela Vista). Essas localizações reforçam o processo de segregação socioespacial na produção do espaço urbano da cidade, já deflagrado em anos anteriores.

Entre esses conjuntos, quatro se localizam na franja urbana, havendo grande distância do centro da cidade e acessibilidade reduzida, o que também contribui para a expansão e fragmentação urbanas. o Bela Vista é o único empreendimento que se situa em vazio urbano, na região norte da malha, junto à Secretaria Municipal de Obras e próximo a loteamentos de interesse social.

Dos conjuntos analisados, quatro empreendimentos são condomínios fechados, cujo modelo induz ao isolamento da vizinhança imediata, reproduzindo valores relacionados à segurança e status, tal qual nos condomínios de alta renda. Observa-se que nos casos analisados, o marketing que associa condomínio à segurança também tem atingido as camadas mais pobres da sociedade, reproduzindo os "enclaves fortificados" tão discutidos por Caldeira (2003), ainda que em menor escala. 0 desinteresse da administração pública em restringir a aprovação desses "enclaves" urbanos propicia sua reprodução.

Nos processos de aprovação desses conjuntos junto à Secretaria de Planejamento da Prefeitura Municipal de Presidente Prudente, não foram consideradas as zonas vigentes, devendo exclusivamente as construtoras proponentes realizarem a adequação do projeto por meio da aquisição da área, assim como a análise dos índices dessas zonas. Segundo a Lei de Uso e Ocupação do Solo então vigente (Lei Complementar n. 128/2003), apenas os conjuntos residenciais Bela Vista, Esmeralda e Monte Carlo foram implantados em zona de uso permitido. À época de aprovação desses empreendimentos era proibida a aprovação e execução de empreendimento de habitação de interesse social em ZR1 (zona residencial de baixa densidade populacional, de ocupação horizontal), local de implantação do Conjunto Residencial Atalaia. Nesse caso, com o agravante de ser conjunto vertical em área de ocupação horizontal de baixa densidade.

Dessa forma, verifica-se que a Prefeitura Municipal de Presidente Prudente não teve participação direta na definição dos empreendimentos financiados pelo PAR na cidade; não auxiliou na definição de áreas, uma vez que não a possuía análise urbana para embasar diretrizes de escolha; e muito menos articulou a definição das áreas de demandas ao deficit habitacional. Sua ação foi passiva nos processos analisados.

Observa-se também que o poder público local não agiu de forma proativa com controle, planejamento e gestão públicos adequados e inclusivos. 
Por fim, a análise dos cinco casos de conjuntos habitacionais financiados pelo PAR em Presidente Prudente possibilitou verificar a falta de controle sobre a oferta e a demanda de habitação na cidade, resultando em uma produção segregada e excludente do espaço urbano, dirigida pelo capital privado.

\section{Considerações finais}

Por meio da análise dos planos diretores aprovados no município e da legislação complementar, pôde-se verificar que a política urbana implementada em Presidente Prudente deixa lacuna quando trata dos instrumentos urbanísticos e das políticas setoriais, principalmente da política habitacional. 0 município carece de uma política urbana inclusiva, em prol de uma cidade menos segregada, com aplicação de instrumentos que sejam utilizados na tentativa de diminuir a especulação imobiliária e possibilitar o controle da expansão urbana periférica e segregada ocorrido nas últimas décadas.

A política habitacional municipal, atualmente, tem nos agentes privados a base para provisão e gestão da habitação social, e a atuação do poder público local evidencia uma omissão em relação à pratica desses agentes e, consequentemente, a desarticulação entre a política urbana e a produção habitacional para a população de baixa renda.

0 modelo de empreendimento contribui para a expansão e fragmentação urbana do território municipal, pois se vincula às localizações mais distantes do centro, junto à franja urbana.

Por fim, a análise dos empreendimentos residenciais financiados pelo Programa de Arrendamento Residencial em Presidente Prudente evidenciou a ausência de políticas públicas - urbana e habitacional - voltadas ao cumprimento da função social da cidade. Percebeu-se também o processo de produção do espaço urbano cada vez mais orientado pelos interesses do capital, o que contribui para a expansão da malha urbana de forma segregada e fragmentada.

Conclui-se que a produção do espaço urbano nesse município é produto direto do capital, não havendo interesse de controle ou planejamento pelo Governo Municipal, sendo fruto da ausência de uma política urbana socialmente justa e equitativa.

\section{Referências}

ABREU, D. S. Poder político local no populismo: Presidente Prudente (SP) 1928-1959. Presidente Prudente: Impress, 1996.

ALVIM, A. T. B.; CASTRO L. G. R.; ZIONI, S. Avaliação de políticas urbanas. In: ALVIM, A. T. B.; CASTRO, L. G. R. (Org.). Avaliação de políticas urbanas - contexto e perspectivas. São Paulo: Ed. Mackenzie, Ed. Romano Guerra, 2010. p. 13-41.

BONATES, M. F.O Programa de Arrendamento ResidencialPAR: acesso diferenciado à moradia e à cidade. Revista RISCO - PPG/DAU/EESC/USP, v. 7, n. 1, 2008. p. 147164. Disponível em: <www.arquitetura.eesc.usp.br/ revista_risco/Risco7-pdf/02_art10_risco7.pdf>. Acesso em: 8 nov. 2008.

CAIXA ECONÔMICA FEDERAL. Cartilha do PAR - Módulo Arrendamento. 2008. Disponível em: <www1.caixa.gov. br/gov/gov_social/estadual/programas_habitacao/par/ index.asp>. Acesso em: 8 dez. 2008.

CALDEIRA, T. P. R. Cidade de muros: crime, segregação e cidadania em São Paulo. 2. ed. São Paulo: Editora 34, EDUSP, 2003.

CORRÊA, R. L. O espaço urbano. 4. ed. São Paulo: Editora Ática, 1999.

CUNHA, E. P.; CUNHA, E. S. M. Políticas públicas sociais. In: CARVAlHO, A. et al. (Org.). Políticas públicas. Belo Horizonte: UFMG, Proex, 2002. p. 11-26.

FELDMAN, S. Política urbana e regional em cidades não-metropolitanas. In: GONÇALVES, M. F.; BRANDÃO, C. A.; GALVÃO, A. C. F. (Org.). Regiões e cidades, cidades nas regiões: o desafio urbano-regional. São Paulo: Ed. da Unesp, Anpur, 2003. p. 105-112.

FERNANDES, S. A. S. Territorialização das políticas habitacionais em Bauru e Presidente Prudente - a atuação da CDHU, COHAB-CRHIS e COHAB-Bauru. 1998. 248 f. Dissertação (Mestrado em Geografia) - Faculdade de Ciências e Tecnologia, Universidade Estadual Paulista, Presidente Prudente, 1998.

FUNDAÇÃO SISTEMA ESTADUAL DE ANÁLISE DE DADOS - SEADE. Grupos de Vulnerabilidade Social Município de Presidente Prudente - 2000. Disponível em: <www.seade.gov.br/produtos/ipvs/analises/presidenteprudente.pdf>. Acesso em: 4 jun. 2008. 
HONDA, S. C. A. L. A centralidade urbana em Presidente Prudente. 2000. 141 f. Dissertação (Mestrado em Arquitetura e Urbanismo Faculdade de Arquitetura e Urbanismo) - Universidade Presbiteriana Mackenzie, São Paulo, 2000.

HONDA, S. C. A. L. Habitação de Baixa Renda como Produto do Capital: o Programa de Arrendamento Residencial (PAR) em Presidente Prudente. 2011. 204 f. Tese (Doutorado em Arquitetura e Urbanismo) Faculdade de Arquitetura e Urbanismo, Universidade Presbiteriana Mackenzie, São Paulo, 2011.

LACAZE, J. P. A cidade e o urbanismo. Lisboa: Instituto Piaget/BBCC, 1999.

MARISCO, L. M O. Contribuição ao estudo do planejamento municipal no Brasil: o Plano Diretor de Desenvolvimento Integrado de Presidente Prudente (SP) 1969. 1997. 276 f. Dissertação (Mestrado em Geografia) Faculdade de Ciências e Tecnologia, Universidade Estadual Paulista, Presidente Prudente, 1997.

MARISCO, L. M. O. A norma e o fato: abordagem analítica da segregação sócio-espacial e exclusão social a partir dos instrumentos urbanísticos. 2003. 212 f. Tese (Doutorado em Geografia) - Faculdade de Ciências e Tecnologia, Universidade Estadual Paulista, Presidente Prudente, 2003.

MARQUES, E. A dinâmica imobiliária de incorporação em período recente. In: MARQUES, E.; TORRES, H. (Org.). São Paulo: segregação, pobreza e desigualdades sociais. São Paulo: Ed. SENAC, 2005. p. 213-240.

MINISTÉRIO DAS CIDADES. Política Nacional de Habitação. Nov. 2004. Disponível em: <www.cidades.gov. $\mathrm{br} / \mathrm{secretarias-nacionais/secretaria-de-habitacao/poli-}$ tica-nacional-de-habitacao>. Acesso em: 23 jun. 2009.

MONTEIRO, J. V. Fundamentos da política pública. Rio de Janeiro: Ipea, Inpes, 1982.

ROLNIK, R.; PINHEIRO, O. M. (Coord.). Plano Diretor Participativo - guia para a elaboração pelos municípios e cidadãos. Brasília: CONFEA, Ministério das Cidades, 2004. Disponível em: <www.viaciclo.org.br/portal/documentos/ doc_details/148-guia-elaboracao-plano-diretor-participativo-min-cidadesconfea>. Acesso em: 1 nov. 2008.
SANTOS, M. A urbanização brasileira. 5. ed. São Paulo: EDUSP, 2005.

SPÓSITO. E. S. Produção e apropriação da renda fundiária urbana em Presidente Prudente. 1990. 230 f. Tese (Doutorado em Geografia) - Faculdade de Filosofia, Letras e Ciências Humanas, Universidade de São Paulo, São Paulo, 1990.

SPÓSITO, M. E. B. 0 'chão' em Presidente Prudente: a lógica da expansão territorial urbana. 1983. $230 \mathrm{f}$. Dissertação (Mestrado em Geografia) - Instituto de Geociências e Ciências Exatas, Universidade Estadual Paulista, São Carlos, 1983.

TORREZAN, R. M. Reestruturação da cidade: localização de conjuntos habitacionais, estrutura e crescimento urbano em Presidente Prudente. 1992. 91 f. Monografia (Graduação em Geografia) - Faculdade de Ciências e Tecnologia, Universidade Estadual Paulista, Presidente Prudente, 1992.

VALLADARES, L. P. (Org.). Repensando a habitação no Brasil. Rio de Janeiro: Zahar Editores, 1983.

VILLAÇA, F. Espaço intra-urbano no Brasil. São Paulo: Studio Nobel/FAPESP, 1998.

VILLAÇA, F. Uma contribuição para a história do planejamento urbano no Brasil. In: DÉAK, C.; SCHIFFER, S. R. (Org.). 0 Processo de urbanização no Brasil. São Paulo: EDUSP, 1999. p. 169-243.

Recebido: 22/01/2012

Received: 01/22/2012

Aprovado: 05/02/2013

Approved: 02/05/2013 